\title{
Rapid urbanization effect on local climate: intercomparison of climate trends in Shenzhen and Hong Kong, 1968-2013
}

\author{
Lei $\mathrm{Li}^{1}{ }^{1}$, Pak Wai Chan ${ }^{2, *}$, Deli Wang ${ }^{1}$, Mingyan $\operatorname{Tan}^{1}$ \\ ${ }^{1}$ Shenzhen National Climate Observatory, Meteorological Bureau of Shenzhen Municipality, \\ Shenzhen Key Laboratory of Severe Weather in South China, Shenzhen 518040, PR China \\ ${ }^{2}$ Hong Kong Observatory, 998000 Kowloon, Hong Kong SAR
}

\begin{abstract}
An intercomparison of climate trends between 2 adjacent large cities, Shenzhen and Hong Kong, in the past 46 yr (1968-2013) suggests that the rate of urbanization is clearly reflected in the rate of the change in local climate. Since becoming a special economic zone in 1980, Shenzhen has experienced a very rapid urbanization process. In only $30 \mathrm{yr}$, Shenzhen has transformed from a small town into a metropolis rivaling Hong Kong. The gross domestic product and urban built-up area in Shenzhen have increased rapidly. Climate data analysis over the last $46 \mathrm{yr}$ showed a greater rate of change in climate in Shenzhen than in Hong Kong over the same period. In Shenzhen, average annual temperature warmed by $1.63 \pm 0.18^{\circ} \mathrm{C}\left(\sim 0.35 \pm 0.04^{\circ} \mathrm{C}\right.$ per decade), average maximum temperature increased by $0.90 \pm 0.19^{\circ} \mathrm{C}$, average minimum temperature increased by $2.09 \pm 0.23^{\circ} \mathrm{C}$ and the diurnal temperature range (DTR) decreased by $1.18 \pm 0.23^{\circ} \mathrm{C}$. Over the same period in Hong Kong, average temperature increased by $0.47 \pm 0.20^{\circ} \mathrm{C}(\sim 0.10 \pm$ $0.04^{\circ} \mathrm{C}$ per decade), maximum temperature increased by $0.12 \pm 0.28^{\circ} \mathrm{C}$, minimum temperature increased by $0.55 \pm 0.20^{\circ} \mathrm{C}$ and DTR decreased by $0.43 \pm 0.27^{\circ} \mathrm{C}$. In addition, relative humidity in Shenzhen decreased by $13.13 \pm 1.78 \%$ in the last $46 \mathrm{yr}$, while there were no significant changes in Hong Kong. Finally, data analysis showed that urbanization has no significant effect on total rainfall for both cities.
\end{abstract}

KEY WORDS: Rapid urbanization $\cdot$ Local climate $\cdot$ Climate change $\cdot$ Shenzhen $\cdot$ Hong Kong

\section{INTRODUCTION}

Knowledge of the urbanization effect on climate is essential in designing climate-friendly cities (Eliasson 2000, Masson et al. 2013). The study of the effect of urbanization on local climate can be traced back to the early 19th century. Howard (1833) reported the discovery of an urban heat island, where air temperature is higher in urban areas than in rural areas, in London. Howard's study was generally taken as the start of the study of the urban effect on local climate, in which air temperature is always the focus, and some studies show that the urban-rural air temperature difference can reach as high as $12^{\circ} \mathrm{C}$ in clear,

\footnotetext{
${ }^{*}$ Corresponding author: pwchan@hko.gov.hk
}

calm nights (Oke 1981). The air temperature difference between urban and rural areas can be attributed to the different thermal processes over different land surfaces; a comprehensive summary on the physical mechanism of the urban warming process can be found in Grimmond (2007). However, air temperature is not the only climate element influenced by urbanization. Because of changes in the physical properties of land surfaces (such as heat capacity, albedo and roughness) and the activities of humans (such as industrial processes and transportation of people and goods), wind characteristics and exchanges of energy and substances between the atmosphere and land surface in urban areas are quite

() The authors 2015. Open Access under Creative Commons by Attribution Licence. Use, distribution and reproduction are unrestricted. Authors and original publication must be credited. 
different from those in rural areas, which significantly influences the wind (i.e. Bornstein \& Johnson 1977, Goldreich \& Surridge 1988, Cheng \& Hu 2005), humidity (i.e. Chandler 1967, Lee 1991) and precipitation (i.e. Oke 1987, Kaufmann et al. 2007) over urban areas.

In the last decade, China has become the focus of attention in the field of urbanization effect on climate (Li et al. 2004, Zhou et al. 2004, Kaufmann et al. 2007, Chen et al. 2011, Ge et al. 2013, Yu et al. 2013). Benefiting from the 'reform and opening' strategy implemented in the early 1980s, China's economy developed rapidly over the last 3 decades. Along with this rapid economic growth, the urbanization process in China was also rapid. Official statistics show that the urban population in China in 2011 was around 691 million, more than 3 times the figure in 1980 (Chinese Academy of Social Sciences 2011).

Among all of the cities in China, Shenzhen is especially notable because it was designated as the first special economic zone (SEZ) in China. Shenzhen is famous for its drastically rapid urbanization after establishment of the SEZ in 1980, and is possibly one of the fastest growing urban areas in the world. Over the last $35 \mathrm{yr}$, Shenzhen transformed from a small town to a megacity, its population increased by around 30 times and its gross domestic product (GDP) by more than 1000 times. At the same time, the landscape also experienced significant changes. Thus, a study on the impact of urbanization on local climate in Shenzhen will further enhance understanding in this field. Some previous studies (Zhou et al. 2004, Chen et al. 2011) of the urbanization effect on climate in China mentioned the rapid urbanization of Shenzhen but did not provide a detailed analysis of its climate trends. Hong Kong, another large city, is located directly adjacent to Shenzhen and has a quite different urbanization process from that of Shenzhen in the same period from the 1970s onwards; therefore, an intercomparison of climate trends between Shenzhen and Hong Kong would be especially helpful to study the impact of rapid urbanization on local climate.

\section{BRIEF DESCRIPTION OF DATA}

\subsection{Meteorological data}

Although there are currently numerous automatic weather stations in Shenzhen and Hong Kong, the meteorological data used herein were collected from the Shenzhen Caiwuwei Weather Station (CWW) and Hong Kong Observatory (HKO), which have the longest continuous climate data records for each city. The locations of the 2 stations are shown in Fig. 1. The elevations above sea level for the CWW and HKO are 18.5 and $32 \mathrm{~m}$, respectively, and all observations were performed at fixed heights during the period of study. According to the 'local climate zone' (LCZ) classification system by Stewart \& Oke (2012), both stations are currently located in LCZ1 (compact high-rise).

Data ranged from 1968 to 2013 and included elements such as $6 \mathrm{~h}$ temperature (daily at 02:00, 08:00, 14:00 and 20:00 h local sidereal time), daily relative humidity and daily precipitation. Data collection at the CWW is in accordance with ground-based observation specifications issued by the China Meteorological Administration, and the HKO is in accordance with HKO operational standards. Data quality from both sources was carefully scrutinized.

Yearly average data during 1968-2013 were calculated from the aforementioned $6 \mathrm{~h}$ and daily data, which include annual average temperature, annual average maximum temperature (at 14:00 h LST), annual average minimum temperature (at 02:00 h LST), annual average diurnal temperature range (DTR, difference in temperatures at 02:00 and 14:00 h), annual average relative humidity and total annual rainfall.

\subsection{Urbanization data}

Population and GDP data from 1979 to 2012 were used to quantify the urbanization process in Shenzhen and Hong Kong and were sourced from the Statistics

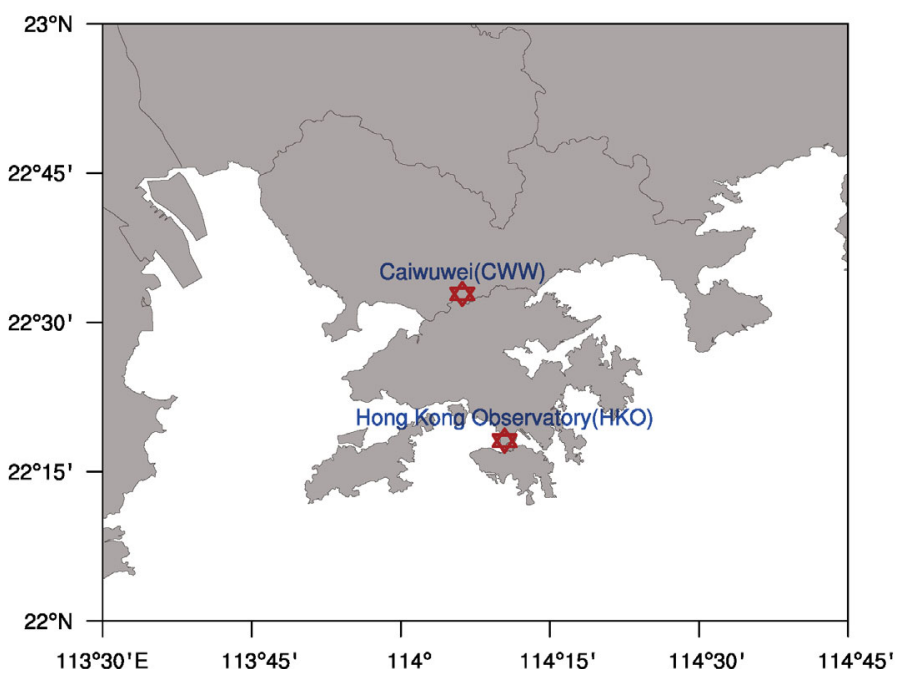

Fig. 1 Locations of the 2 meteorological stations in Hong Kong and Shenzen 
Bureau of Shenzhen Municipality and the Hong Kong Census and Statistics Department, respectively. This data range was chosen because the Shenzhen SEZ was established in 1980, and 1979 was selected as the base year for urbanization data; also, official urban development statistics in Shenzhen only began in 1979. In addition to population and GDP, this study also collected data on the size of the built-up area in both cities for some of the years, and data were also sourced from the Urban Planning and Design Institute of Shenzhen and the Hong Kong Census and Statistics Department. To further identify the urbanization process, Landsat satellite data in 1986, 1995 and 2005 were collected to analyze vegetation degradation and urban expansion in Shenzhen.

\section{URBAN PROCESSES IN THE LAST 33 YEARS}

At the end of 2012, Shenzhen's administrative area was $1996.85 \mathrm{~km}^{2}$ and Hong Kong's was $1108 \mathrm{~km}^{2}$. In this section, data on population growth, GDP and built-up area of the 2 cities are used to demonstrate the different courses of development in the past $33 \mathrm{yr}$.

\subsection{Population}

Fig. 2 shows the population growth in Shenzhen and Hong Kong between 1979 and 2012. As shown, Hong Kong's population variation was relatively flat and only grew from 5.02 million to 7.17 million in $33 \mathrm{yr}, \mathrm{a} 1.12 \%$ compound annual growth rate (CAGR). In contrast, Shenzhen experienced a population explosion; in 1979, there were 0.37 million people, only $7.3 \%$ of Hong Kong's population. By 2000, Shenzhen's population exceeded Hong Kong's, and

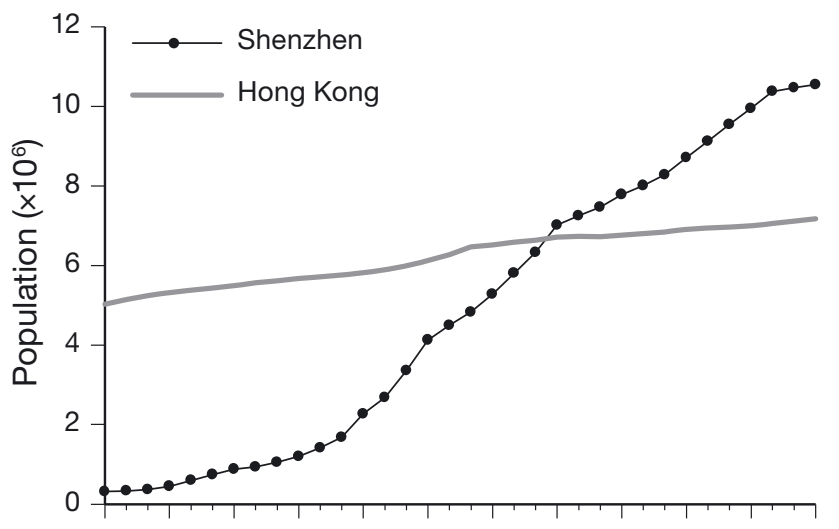

197919821985198819911994199720002003200620092012

Fig. 2. Population during 1979-2012 in Shenzhen and Hong Kong by 2012, official data showed 10.54 million people, 1.47 times Hong Kong's population. Shenzhen's population grew at $11.03 \%$ CAGR in these 33 yr. Even more astonishing is that some unofficial statistics considered 10.54 million a serious underestimate, and if migrant workers are taken into account, Shenzhen's actual population might exceed 14 million.

\subsection{GDP}

Gross domestic product (GDP) is another indicator used to reflect the pace of city development, and Fig. 3 shows the GDP trends of both cities between 1979 and 2012. Both cities experienced rapid growth over the past 33 yr. Hong Kong's GDP grew from 112.7 billion Hong Kong dollars (HKD) in 1979 to HKD 2 trillion in 2012, a CAGR of $9.47 \%$; Shenzhen's GDP grew from 196 million Chinese yuan (CNY) to CNY 1.3 trillion over the same period, a CAGR of $31.64 \%$. Even as Hong Kong went into a recession and GDP declined after the Asian financial crisis in 1997, Shenzhen was unaffected and maintained rapid growth in GDP. The GDP data illustrated here have not been adjusted for inflation because of the limited data available for Shenzhen. However, the comparison of nominal GDP data is still meaningful, since they reflect the continuous development of economies in the 2 cities year by year.

\subsection{Built-up area}

Compared to population and GDP data, consistent and continuous data on the size of built-up area is more difficult to obtain. Table 1 lists the size of built-

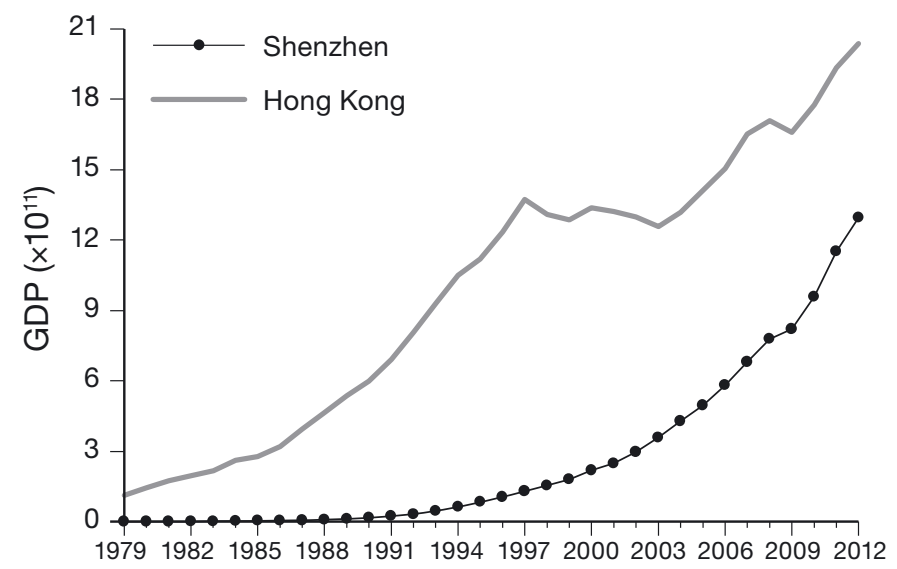

Fig. 3. Gross domestic product (GDP) during 1979-2012 in Shenzhen (in Chinese yuan) and Hong Kong (in Hong Kong dollars) 
Table 1. Built-up area (any land on which buildings, nonbuilding structures, roads and/or squares are present) of Shenzhen and Hong Kong in different years $\left(\mathrm{km}^{2}\right)$

\begin{tabular}{|lcc|}
\hline Year & Shenzhen & Hong Kong \\
\hline 1980 & 12.46 & 166.58 \\
1994 & 375.05 & $213.44^{\mathrm{a}}$ \\
2005 & 629.01 & 264.00 \\
2012 & 862.80 & 265.00 \\
& \\
& \\
& No data for 1994, therefore 1993 data used for comparison \\
\hline
\end{tabular}

up areas for both cities in 4 separate years. The trend for urban built-up area was relatively flat in Hong Kong, while Shenzhen's growth was very rapid.

In addition to statistical data, urbanization and changes in vegetation can also be described by the normalized difference vegetation index (NDVI) retrieved from satellite data (Lenney et al. 1996, Chen et al. 2006, Stellmes et al. 2013). Fig. 4 shows the change in NDVI over Shenzhen in 3 different years and depicts the evolution of vegetation degradation and urban expansion in Shenzhen. The NVDI data in Fig. 4 were retrieved from Landsat thematic mapper data, in which a negative value indicates ground covered by clouds or water, a larger number represents greater green coverage and a value of 0 to 0.2 denotes bare soil and urban land. Since cloud cover is more intense over southern China, it is difficult to locate satellite images in which the entire Shenzhen area had clear sky; thus, the images in Fig. 4 are made up of images from 2 temporally close days in the same year. For instance, the 1986 image combined those from November 3 and 28, 1986; the 1995 image combined those from December 7 and 30, 1995; and the 2005 image combined those from November 16 and 23, 2005.

Fig. 4 clearly shows the process of urban expansion in Shenzhen over the years. In 1985, when the SEZ had been established for just $5 \mathrm{yr}$, only the southwestern coastal areas had a dense built-up area, whereas northwestern and northeastern areas were still in their early developmental stages and therefore had relatively higher vegetation coverage. By 1995, the urban built-up area expanded greatly, and northeastern inland and northwestern coastal areas were gradually transformed into visible built-up areas. By 2005, the built-up area had further expanded in northwestern Shenzhen. Throughout the process of urban expansion, not only was vegetation cover reduced but reclamation along the western coastline had transformed part of the ocean into construction sites.

The evolution of land use has significantly changed the surroundings of the 2 weather stations. Based on the LCZ classification system, during the last $35 \mathrm{yr}$, the HKO had moved from LCZ2 (compact mid-rise) to LCZ1 (compact high-rise), while the CWW of Shenzhen had moved from LCZ6 (open low-rise) to LCZ1.
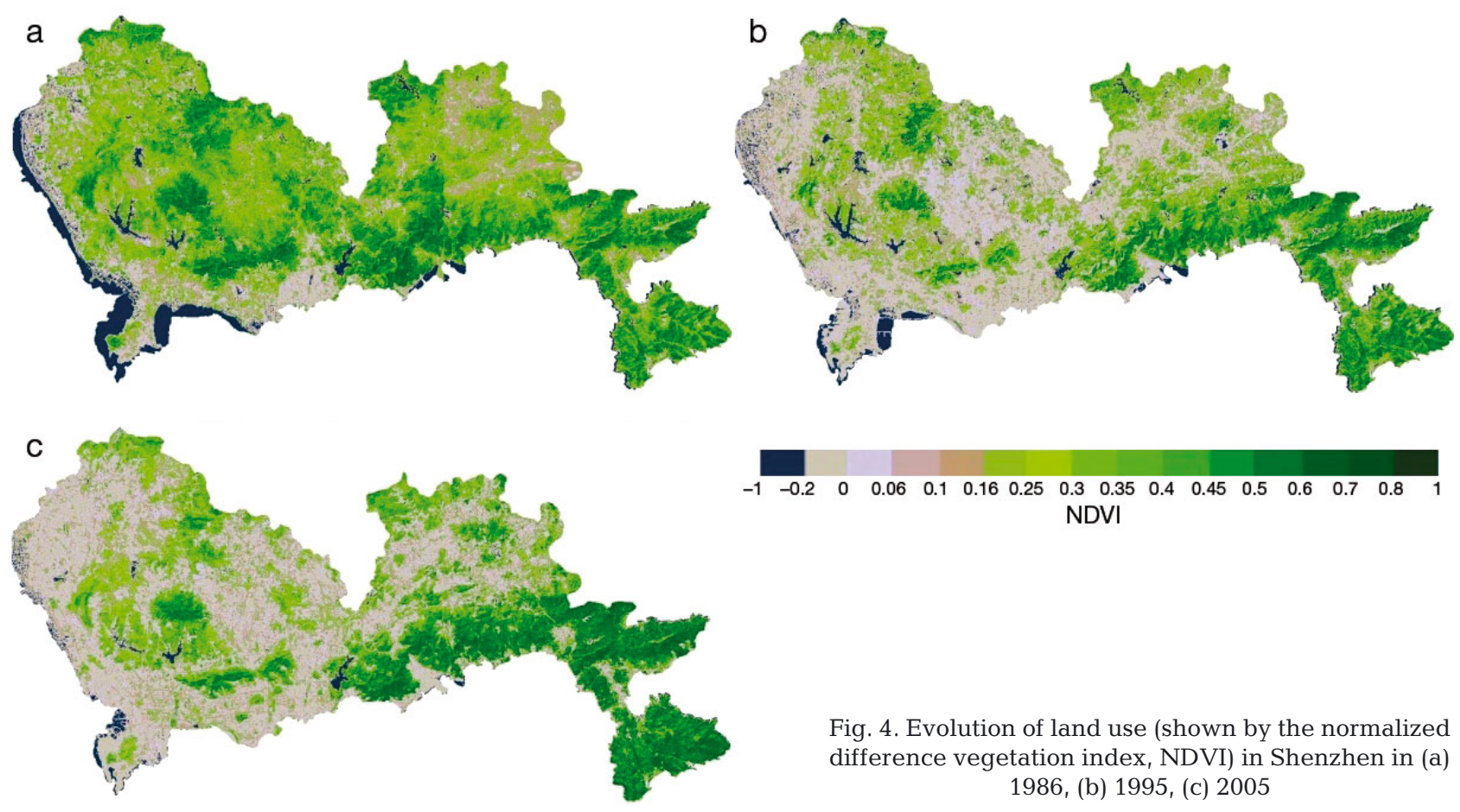

Fig. 4. Evolution of land use (shown by the normalized difference vegetation index, NDVI) in Shenzhen in (a) 1986, (b) 1995, (c) 2005 
In terms of the changes of economic, population and built-up area, Shenzhen and Hong Kong experienced very different processes of urbanization in the last 33 yr. In 1979, Hong Kong was already a developed economy and was known as one of the 4 Asian Tigers, whereas Shenzhen was an underdeveloped small town, with an economy and population that were incomparable with those of Hong Kong. The built-up area in Shenzhen in 1979 was less than 10\% of Hong Kong's and accounted for less than $1 \%$ of the entire Shenzhen administrative area. By 2012, although Hong Kong remained one of the most dynamic economies in the world, Shenzhen's population and built-up area had already exceeded that of Hong Kong, and its economy had reached a level comparable with that of Hong Kong.

\section{INTERCOMPARISON OF CLIMATE TRENDS}

\subsection{Average air temperature $\left(T_{a}\right)$}

Variations in average annual $T_{\mathrm{a}}$ in Shenzhen and Hong Kong are illustrated in Fig. 5. During 19681978, Shenzhen's average $T_{\mathrm{a}}$ was always lower than Hong Kong's by about $1^{\circ} \mathrm{C}$. From 1978 onwards, the gap between average $T_{\mathrm{a}}$ in these 2 cities began to shrink and became very similar by 1990. After 2006, Shenzhen's average $T_{\mathrm{a}}$ regularly exceeded Hong Kong's by 0.1 to $0.4^{\circ} \mathrm{C}$.

Linear least-squares regression (LLSR) was used in this study to detect any significant trend in climate change, and this method has been successfully applied in several previous studies (Li et al. 2004, Zhou et al. 2004, Chen et al. 2011). According to Hamburg (1977), the LLSR equation is expressed as:

$$
Y=a+b X
$$

where $Y$ represents meteorological elements (such as air temperature), and $X$ represents year. The coefficients $a$ and $b$ are calculated as follows:

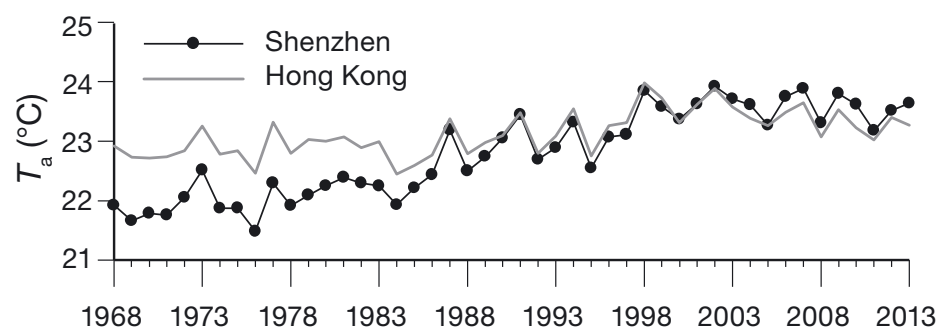

Fig. 5. Yearly average air temperature ( $\left.T_{\mathrm{a}}\right)$ during 1968-2013 in Shenzhen and Hong Kong

$$
\begin{gathered}
a=\bar{y}-b X \\
b=\frac{\sum_{i=1}^{n} x_{i} y_{i}-n \bar{x} \bar{y}}{\sum_{i=1}^{n} x_{i}^{2}-n \bar{x}^{2}}
\end{gathered}
$$

where $\bar{y}$ and $\bar{x}$ are the average value of samples $x_{i}$ and $y_{i}$, and $\mathrm{n}$ is the sample size.

To evaluate the confidence level (CL) from the linear trend derived from the LLSR method, the correlation coefficient of the linear regression is calculated as follows:

$$
\mathrm{r}=\frac{\sum_{i=1}^{n}\left(x_{i}-\bar{X}\right)\left(y_{i}-\bar{y}\right)}{\sqrt{\left(\sum_{i=1}^{n}\left(x_{i}-\bar{X}\right)^{2}\right)\left(\sum_{i=1}^{n}\left(y_{i}-\bar{y}\right)^{2}\right)}}
$$

The value of $\mathrm{r}^{2}$ represents the proportion of variance in $Y$ in Eq. (1) and is called the sample coefficient of determination. Then, the test statistic, $t$, can be calculated as follows:

$$
t(\mathrm{r}, n)=\frac{|\mathrm{r}| \sqrt{n-2}}{\sqrt{1-\mathrm{r}^{2}}}
$$

where, $t(r, n)$ is the point on the Student's $t$ distribution for the degrees of freedom $(n-2)$ and correlation coefficient r. Subsequently, the CL $(=1-\alpha)$ is calculated as follows:

$$
1-\alpha=\int_{-t(r, n)}^{t(r, n)} f(t, n) d t
$$

where $f(t, n)$ is the probability density function of the test, and $\alpha$ is the significance level.

For $T_{\mathrm{a}}$, the linear warming trend in both cities passed the significance test at $0.01 \mathrm{CL}$; thus, warming in both cities was significant in the past $46 \mathrm{yr}$. To estimate the magnitude of warming in both cities, average temperatures were calculated for the first and last $10 \mathrm{yr}$ of the time period, $T_{1968-1977}$ and $T_{2004-2013}$. Then, the magnitude of warming over the past 46 yr was determined by subtracting $T_{1968-1977}$ from $T_{2004-2013}$.

To estimate the statistical uncertainty range of climate trends, a time series of $10 \mathrm{yr}$ moving average air temperature, say $T_{1968-1977}, T_{1969-1978}, T_{1970-1979}, \ldots$, $T_{2004-2013}$, was reconstructed. A new regression equation for $10 \mathrm{yr}$ moving average air temperature can be derived, and the uncertainty range of the regression coefficients, namely, $b$, in Eq. (3) for the new time series at $0.01 \mathrm{CL}$ can be calculated by using a method introduced by Lane (2014), which was consequently used to estimate the uncertainty range of climate trends. The method used to estimate the uncertainty range of the air temperature trend was also applied to other meteorological elements hereafter. 
Considering the uncertainty range, the air temperature in Hong Kong rose by $0.47 \pm 0.20^{\circ} \mathrm{C}$ in the past 46 yr at a rate of $0.10 \pm 0.04^{\circ} \mathrm{C}$ per decade, while temperature in Shenzhen rose by $1.63 \pm 0.18^{\circ} \mathrm{C}$ at a rate of $0.35 \pm 0.04^{\circ} \mathrm{C}$ per decade. The increased value of Shenzhen's air temperature is larger than the global average value provided in the Fifth Assessment Report of the IPCC, which says that the average surface air temperature rose by around $0.85^{\circ} \mathrm{C}$, with an uncertainty range of around $0.2^{\circ} \mathrm{C}$, from 1880 to 2012 (IPCC 2013). Furthermore, in a recent study on air temperature series in China, Wang et al. (2014) estimated that the average temperature trend in the period $1956-2005$ is around $0.252^{\circ} \mathrm{C}$ per decade, with an uncertainty range of around $0.095^{\circ} \mathrm{C}$ per decade. Thus, it can be concluded that Shenzhen's warming rate is also faster than the average warming rate of China.

In addition to calculating the rate of warming, estimating the contribution of urbanization on warming is also important. Chan et al. (2012) used Reanalysis 1 data from the US National Centers for Environment
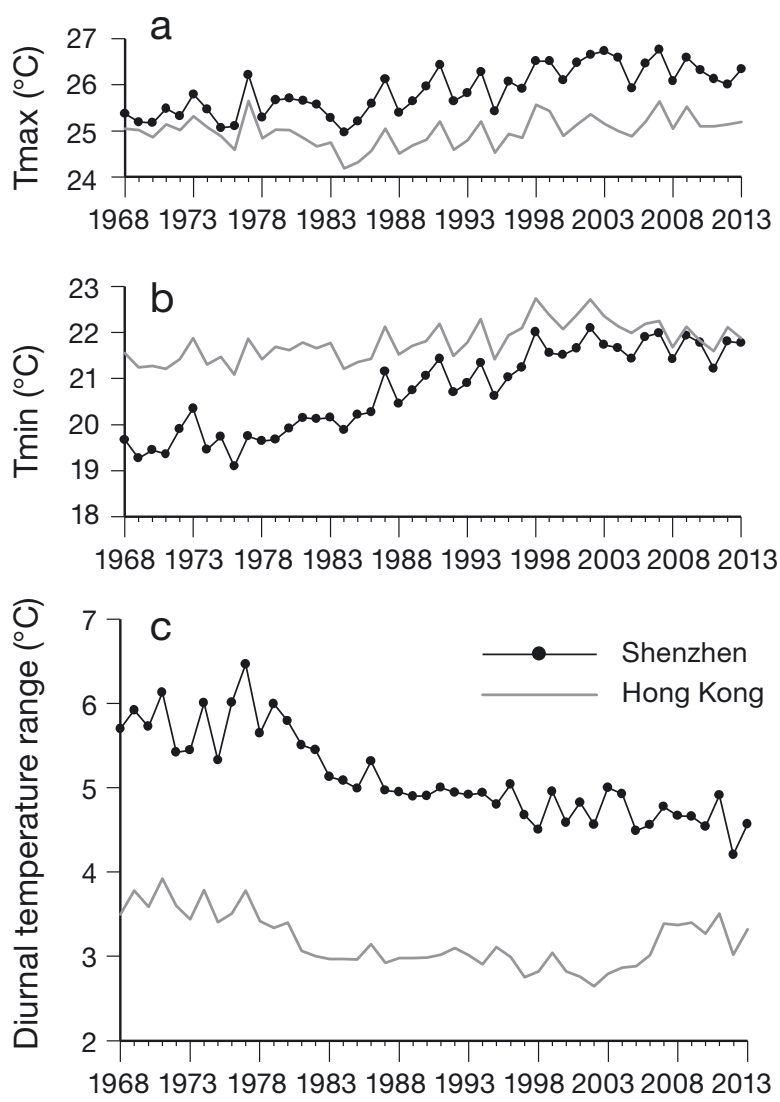

Fig. 6. Yearly average (a) maximum air temperature, (b) minimum air temperature and (c) diurnal temperature range during 1968-2013 in Shenzhen and Hong Kong
Prediction-National Center for Atmospheric Research (NCEP-NCAR), and meteorological observations and sounding data from HKO stations, leading to estimates that urbanization contributed roughly $42.3 \%$ of warming in Hong Kong during 1971-2010. Therefore, using this conclusion, the contribution of 'background factors' other than urbanization (i.e. global warming) for Hong Kong's warming rate is $100.0 \%$ minus $42.3 \%$, i.e. $57.7 \%$. This study assumes that the contribution to warming by the background factors calculated in Chan et al. (2012) is also applicable during 1968-2013, and this assumption is reasonable given that the time periods between the studies are similar. Thus, during 1968-2013, background factors contributed approximately $0.47^{\circ} \mathrm{C}$ multiplied by $57.7 \%$, or $0.27^{\circ} \mathrm{C}$, to warming in Hong Kong. Given that Shenzhen and Hong Kong are neighbors and that the straight-line distance between the CWW and $\mathrm{HKO}$ is only around $30 \mathrm{~km}$, it can be assumed that background factors also contributed $0.27^{\circ} \mathrm{C}$ to warming in Shenzhen. Therefore, contribution by urbanization to warming in Shenzhen is $1.63 \pm$ $0.18^{\circ} \mathrm{C}$ minus $0.27^{\circ} \mathrm{C}$, or about $1.36 \pm 0.18^{\circ} \mathrm{C}$, with a contribution rate of 81.4 to $85.1 \%$, which is quite large, and shows that urbanization is the most important factor driving local warming in Shenzhen.

\subsection{Maximum air temperature, minimum air temperature and diurnal temperature range}

Fig. 6a shows the trends for maximum temperature (Tmax). Over the past $46 \mathrm{yr}$, Tmax in Shenzhen also exhibited a clear uptrend; Tmax rose by $0.90 \pm$ $0.19^{\circ} \mathrm{C}$, and the linear regression on this warming trend passed the significance test at $0.01 \mathrm{CL}$. In contrast, trends for Tmax in Hong Kong are not obvious; Tmax rose by only $0.12 \pm 0.28^{\circ} \mathrm{C}$, and its linear regression failed the significance test at $0.01 \mathrm{CL}$.

Fig. 6b shows the trends for minimum temperature (Tmin). Over the past $46 \mathrm{yr}$, Tmin in Shenzhen rose more than Tmax; Tmin rose by $2.09 \pm 0.23^{\circ} \mathrm{C}$, and the linear regression on this warming trend passed the significance test at 0.01 CL. Similarly, Tmin in Hong Kong also exhibited a more obvious uptrend; Tmin rose by $0.55 \pm 0.20^{\circ} \mathrm{C}$ over the past $46 \mathrm{yr}$. Despite the smaller magnitude of increase in Hong Kong than in Shenzhen, its linear regression also passed the significance test at $0.01 \mathrm{CL}$.

Fig. 6c shows the trends for average diurnal temperature range (DTR). A declining trend for average DTR is exhibited in both Shenzhen and Hong Kong over the past $46 \mathrm{yr}$, and their linear regressions 
passed the significance test at $0.01 \mathrm{CL}$. However, Shenzhen saw a greater decrease in average DTR than Hong Kong; Shenzhen's DTR dropped by $1.18 \pm$ $0.23^{\circ} \mathrm{C}$ during the period 1968-2013, while Hong Kong's average DTR dropped by $0.43 \pm 0.27^{\circ} \mathrm{C}$ over the same period. Comparison between Figs. 5 \& $6 \mathrm{c}$ shows that although annual average temperatures in both cities were similar since the late 1980s, DTRs between the two were still far apart. The average DTR was always lower in Hong Kong, indicating that the climate in Hong Kong exhibited greater oceanic characteristics than that in Shenzhen. Comparison of Figs. 5 \& 6 shows that the declining trends of average DTRs in both cities were mainly contributed by rising minimum temperature, which was consistent with the conclusion of Zhou et al. (2004).

\subsection{Hot days and cold days}

In Shenzhen, $33^{\circ} \mathrm{C}$ is the threshold for issuing a hot weather warning. If the maximum air temperature exceeds $33^{\circ} \mathrm{C}$, a hot weather warning is issued by the Meteorological Bureau of Shenzhen Municipality. Fig. 7 a shows the number of days each year with temperatures at 14:00 $\mathrm{h} \mathrm{LST}$ exceeding $33^{\circ} \mathrm{C}$ in both cities and is hereinafter defined as the metric measuring the change in number of hot days. Fig. 7a shows that the number of hot days rose very quickly in Shenzhen in the past 46 yr. There was an average of only $7.2 \mathrm{~d}$ of hot days annually in 1968-1977, but by $2004-2013$, the average increased by $29.1 \pm 2.3 \mathrm{~d}$, and its linear regression passed the significance test at $0.01 \mathrm{CL}$. During the same period, Hong Kong saw an increase of only $2.1 \mathrm{~d}$ in the number of hot days. However, the statistical uncertainty range is $\pm 33.4 \mathrm{~d}$, and the linear regression failed the significance test at $0.01 \mathrm{CL}$. As the number of hot days increased in Shenzhen, energy consumption increased because of more cooling demand in summer; thus, to some extent, it increased anthropogenic heat emissions and provided positive feedback for further local temperature rises.

Once minimum air temperature falls below $10^{\circ} \mathrm{C}$, the Meteorological Bureau of Shenzhen Municipality issues a cold weather warning urging the public to take precautions against cold weather. Fig. $7 \mathrm{~b}$ shows the number of cold days each year in both cities in the past $46 \mathrm{yr}$, which are derived from the air temperature at 02:00 h LST. The figure shows that the number of cold days has dropped significantly. In 1968-1977, the average annual number of cold days in Shenzhen was around 31.6 d, and in 2004-2013, the number had dropped by $15.5 \pm 5.2 \mathrm{~d}$, and the linear regression for this downtrend passed the significance test at $0.01 \mathrm{CL}$. During the same period, Hong Kong saw a decrease of only $2.5 \pm 2.2 \mathrm{~d}$ in the number of cold days. Not only was the rate of decrease much smaller than in Shenzhen, but its variation trend also failed the significance test at $0.01 \mathrm{CL}$, even though the rising trend of average minimum temperature passed the significance test at $0.01 \mathrm{CL}$.

\subsection{Relative humidity}

Urbanization causes changes in the physical properties of land surfaces and increases the amount of impervious surfaces within built-up areas. Grimmond (2007) pointed out that impervious surfaces reduce water seepage and change the surface hydrograph, leading to more urban floods. In addition, impervious surfaces reduce water content, thereby causing changes in relative humidity (Chandler 1967, Lee 1991). Fig. 8 shows the changes for relative humidity in both cities in the past 46 yr. There were no significant differences between relative humidity in both cities before 1983, but they began to diverge in 1983,
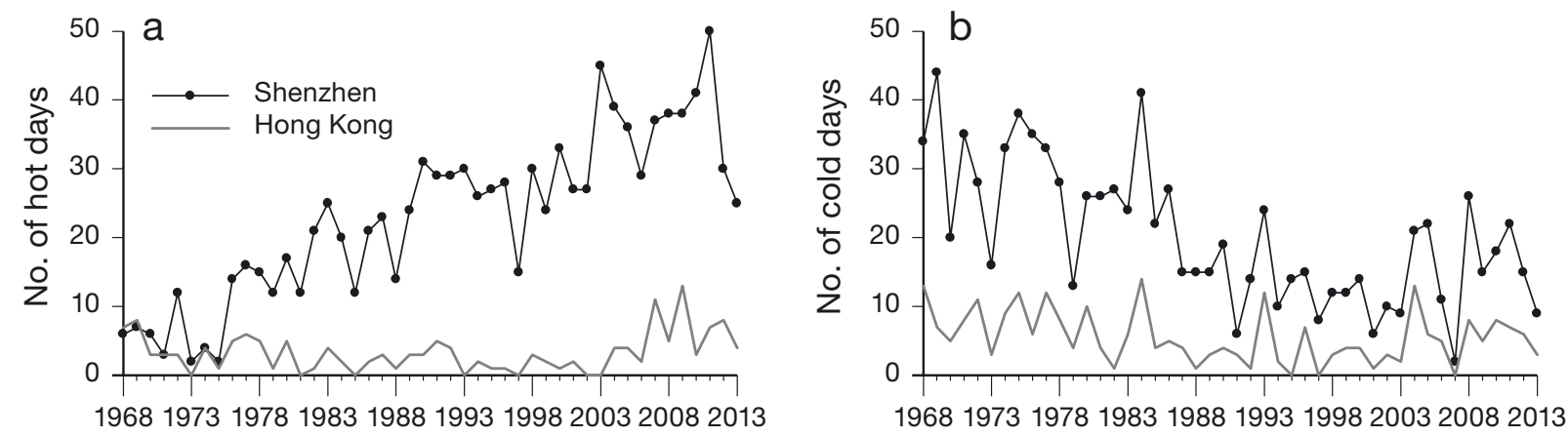

Fig. 7. Number of (a) hot days and (b) cold days during 1968-2013 in Shenzhen and Hong Kong 


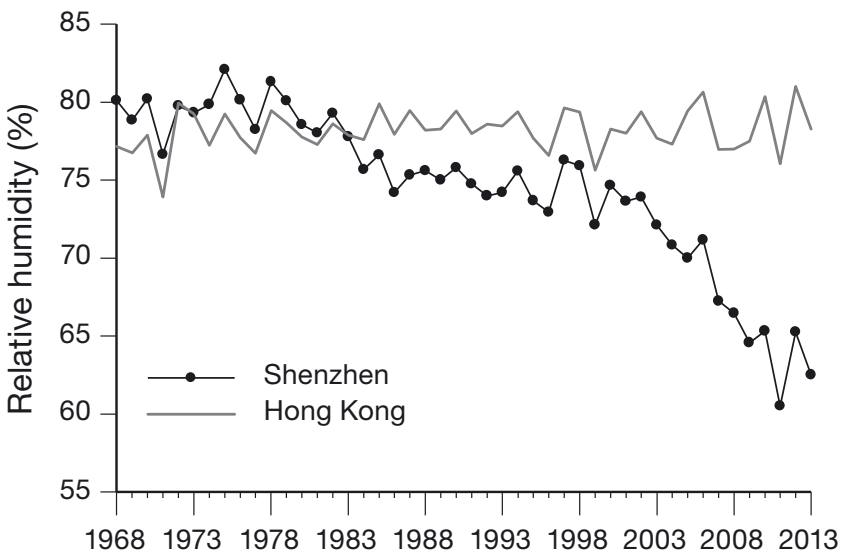

Fig. 8. Relative humidity during 1968-2013 in Shenzhen and Hong Kong

with Hong Kong basically showing no changes and Shenzhen showing a significant decline. In Shenzhen, average relative humidity in 2004-2013 was $13.13 \pm$ $1.78 \%$ lower than the average value in 1968-1977. By the 2010s, Shenzhen's average annual relative humidity was around $12 \%$ lower than the average in Hong Kong, which shows that rapid urbanization had a significant influence on relative humidity in Shenzhen. Two possible explanations why relative humidity in Shenzhen is currently around $12 \%$ lower than it is in Hong Kong are that (1) the ocean has greater influence on Hong Kong's weather, similar to the reason behind the difference in DTRs between the 2 cities; and (2) the percentage of urban built-up area in Hong Kong $(23.92 \%)$ is less than that in Shenzhen $(43.21 \%)$.

\subsection{Precipitation}

In studies of the impact of urbanization on precipitation in the Pearl River Delta, situated in both Shenzhen and Hong Kong, scholars arrived at different conclusions from different perspectives. Based on Landsat and monthly climate data during the period 1988-1996, Kaufmann (2007) discussed the relationship between climate and urban land use in concentric buffers around the sampling stations. He concluded that there is a causal relationship between temporal and spatial patterns of urbanization and temporal and spatial patterns of precipitation during the dry season, leading to an urban precipitation deficit in which urbanization reduces local precipitation. Meanwhile, Chen et al. (2011) analyzed the precipitation time series for a longer period of time and believed there were no significant trends for precipi-

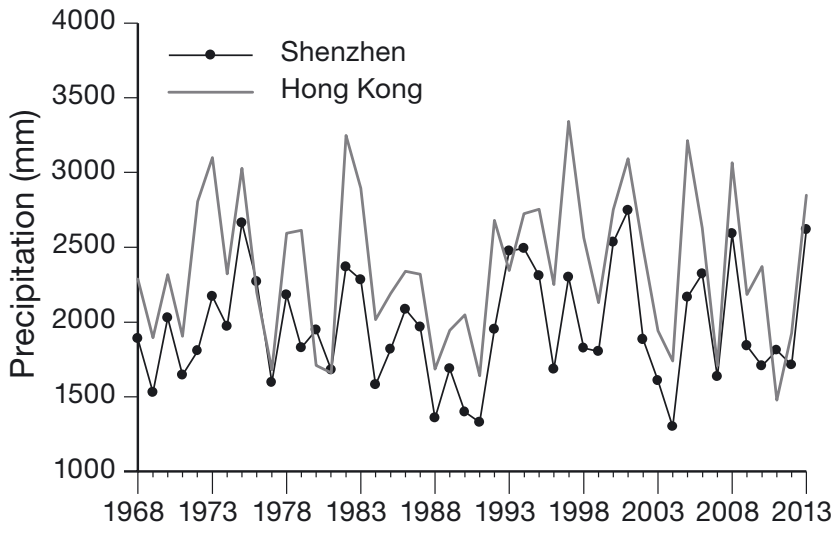

Fig. 9. Yearly precipitation during 1968-2013 in Shenzhen and Hong Kong

tation in the Pearl River Delta region. Fig. 9 shows the time series of annual rainfall between the 2 cities. It shows that Hong Kong had greater overall annual rainfall than Shenzhen, which further illustrates that Hong Kong's climate is impacted by oceans more significantly than Shenzhen's climate, even though the cities are adjacent to each other and the straight-line distance between their 2 weather stations is $\sim 30 \mathrm{~km}$. A trend analysis showed that the linear regression for rainfall failed the significance test at even $0.1 \mathrm{CL}$, indicating that urbanization had no significant effect on total rainfall for both cities, which is consistent with the conclusion of Chen et al. (2011). However, another study based on data from multiple stations (Mok et al. 2006) stated that urbanization has led to spatial variation of rainfall in Hong Kong

\section{ANALYSIS AND DISCUSSION}

The above discussions show that although Shenzhen and Hong Kong are adjacent to each other and the straight-line distance between the $\mathrm{CCW}$ and HKO weather stations is only about $30 \mathrm{~km}$, their recorded climate trends are very different. Since the establishment of the SEZ, Shenzhen has experienced very rapid urbanization, in which population, GDP and urban built-up area surged in a short period of time. During the same period, although Hong Kong was also growing, the rate of development was far slower than that in Shenzhen. This difference in development speed brought a very significant impact on urban climate. In Shenzhen, $T_{\mathrm{a}}$ Tmin, Tmax and number of hot days exhibited an uptrend, while DTR, number of cold days and relative humidity decreased. The linear regression for all variables passed the significance test at $0.01 \mathrm{CL}$. 
Previous findings regarding the effects of urbanization on physical climatic mechanisms can help explain climate change in Shenzhen (Carlson \& Arthur 2000, Grimmond 2007), especially since these effects were particularly marked there. The artificial materials in urban built-up areas often have high heat capacity and low reflectivity, which is conducive to the increase in heat capacity and temperature of land surfaces in Shenzen. Rapid population growth and economic development compound this through anthropogenic heat emission from urban energy consumption, resulting in a faster rise in temperature. Meanwhile, at night, longwave radiation is reflected many times and absorbed by high-rise building walls and ground surfaces, creating a more significant warming effect at night. Therefore, while $T_{\mathrm{a}}$, Tmin and Tmax increased during the period, Tmin rose more than Tmax, leading to a decrease in DTR. At the same time, because of the expansion of impermeable and impervious surfaces, more precipitation resulted in runoff into the sea, reducing the water content of the land surface, resulting in a rapid drop in relative humidity. Although Hong Kong was also growing during this period, the rate of development was far slower, and therefore the change in climate was not as dramatic as that in Shenzhen.

Correlation coefficients between urbanization statistics and climate indicators reflect the differences in the urban effect on climate between Shenzhen and Hong Kong. Because it not affected by factors such as inflation, population data are more suitable than GDP in reflecting the process of urbanization; this study therefore calculated the correlation between population and climatic indicators. Table 2 shows the correlation coefficients between populations of Shenzhen and Hong Kong with the annual averages of 5 climatic indicators over the past 46 yr. From Table 2, the absolute values of the correlation coefficients between Shenzhen's population and all 5 climatic indicators were over 0.7 and passed the significance test at $0.01 \mathrm{CL}_{i} T_{\mathrm{a}}$, Tmin and Tmax showed a

Table 2. Correlation coefficients between population and different climate elements. Means not passing significance test at 0.01 level in bold. DTR = diurnal temperature range; $\mathrm{RH}=$ relative humidity; $T_{\mathrm{a}}=$ air temperature; $T_{\mathrm{m}}=$ minimum air temperature; $T_{\mathrm{M}}=$ maximum air temperature

\begin{tabular}{|lccccc|}
\hline City & $T_{\mathrm{a}}$ & $T_{\mathrm{M}}$ & $T_{\mathrm{m}}$ & $\mathrm{DTR}$ & $\mathrm{RH}$ \\
\hline Shenzhen & 0.82 & 0.71 & 0.84 & -0.72 & -0.83 \\
Hong Kong & 0.60 & 0.59 & 0.54 & $\mathbf{- 0 . 0 1}$ & $\mathbf{0 . 0 1}$ \\
\hline
\end{tabular}

positive correlation with population, while DTR and relative humidity showed a negative correlation. In contrast, although the correlation coefficients between Hong Kong's population and $T_{\mathrm{a}}$, Tmin and Tmax passed the significance test at $0.01 \mathrm{CL}$, the values are significantly lower than those in Shenzhen. Meanwhile, the correlation coefficients between Hong Kong's population and DTR and relative humidity are near zero, which means that there are essentially no relationships between DTR/relative humidity and population growth.

Relationships between the population and climate elements were also analyzed through Granger causality, which is a statistical hypothesis test to determine whether one time series is useful in forecasting another (Granger 1969). In this test, if one time series, $X$, is determined to be useful in forecasting another time series, $Y, X$ can be taken as the Granger-cause of $Y$. In this study, the time series of population was set as $X$ and those of climate elements as $Y$. The lagged value was set as 1 , which means that the response of the climate elements is assumed to be 1 yr later than the variation in population.

The results of the Granger causality test suggest that population is the Granger-cause of the variations in all climate elements in Shenzhen. However, in Hong Kong, population is only the Granger-cause of $T_{\mathrm{a}}$, Tmin and Tmax and seems to have no impact on DTR and relative humidity, which is quite accordant with the results of the correlation analysis.

\section{SUMMARY}

This study compares climate change in the 2 neighboring megacities of Shenzhen and Hong Kong over the past 46 yr (1968-2013). Since these 2 cities have experienced different speeds of urbanization during this period, an intercomparison study on the climate trends in the 2 cities can further enhance our understanding of the impact of rapid urbanization on local climate. This study reached the following conclusions:

(1) Since establishment of the SEZ in 1980, Shenzhen has experienced very rapid urbanization, in which Shenzhen's population and GDP grew at a CAGR of 11.03 and $31.64 \%$, respectively, between 1979 and 2012. In contrast, Hong Kong was already a mature metropolis since the 1960s, in which its population and GDP grew at a CAGR of only 1.12 and $9.47 \%$, respectively, over the same period. Compared to 1980, Shenzhen's urban built-up area expanded by about $6825 \%$, while Hong Kong's in- 
creased by only $59.08 \%$. The rate of urbanization was much faster in Shenzhen than in Hong Kong during the period.

(2) Over the last $46 \mathrm{yr}$, Shenzhen warmed by $1.63 \pm$ $0.18^{\circ} \mathrm{C}$ at a rate of $0.35 \pm 0.04^{\circ} \mathrm{C}$ per decade, while Hong Kong warmed by $0.47 \pm 0.20^{\circ} \mathrm{C}$ at a rate of $0.10 \pm 0.04^{\circ} \mathrm{C}$ per decade. Combined with previous studies in Hong Kong on the contribution of urbanization to warming, it is estimated that urbanization increased Shenzhen's temperature by $1.36 \pm 0.18^{\circ} \mathrm{C}$, with a contribution of 81.4 to $85.1 \%$.

(3) Over the last $46 \mathrm{yr}$, Shenzhen's Tmax increased by $0.90 \pm 0.19^{\circ} \mathrm{C}$, Tmin increased by $2.09 \pm 0.23^{\circ} \mathrm{C}$ and DTR decreased $1.18 \pm 0.23^{\circ} \mathrm{C}$, and their linear regressions passed the significance test at $0.01 \mathrm{CL}$. During the same period, Hong Kong's Tmax increased by $0.12 \pm 0.28^{\circ} \mathrm{C}$, but its linearized warming trend failed the significance test at $0.01 \mathrm{CL}$, while its Tmin increased by $0.55 \pm 0.20^{\circ} \mathrm{C}$ and DTR decreased by $0.43 \pm 0.27^{\circ} \mathrm{C}$, and both linear regressions passed the significance test at $0.01 \mathrm{CL}$. Correspondingly, the number of hot days in a year in Shenzhen increased by $29.1 \pm 2.3 \mathrm{~d}$, and the number of cold days decreased by $15.5 \pm 5.2 \mathrm{~d}$, and both linear regressions passed the significance test at $0.01 \mathrm{CL}$. The number of hot days in a year in Hong Kong increased by only $2.1 \mathrm{~d}$, with an uncertainty range of $\pm 33.4 \mathrm{~d}$, and the number of cold days decreased by $2.5 \pm 2.2 \mathrm{~d}$, but both linear regressions failed the significance test at $0.01 \mathrm{CL}$

(4) Relative humidity in Shenzhen declined by $13.13 \pm 1.78 \%$ over the past $46 \mathrm{yr}$, while that in Hong Kong had no significant change. Furthermore, there were no significant linear trends in rainfall for both cities during the period, and both linear regressions failed the significance test at $0.01 \mathrm{CL}$, indicating that urbanization had no significant impact on total annual rainfall in both cities.

(5) By comparing climatic indicators with urban development in Shenzhen and Hong Kong, it is shown that the pace of urbanization is well reflected on the rate of change in local climate. Rapid urbanization is at least part of the reason for significant changes in local climate in Shenzhen.

Acknowledgements. This study was funded by the National Natural Science Foundation of the People's Republic of China (Grant No. 51278308) and the R\&D Foundation of Shenzhen (Basic Research Project; Grant No. JCYJ 20130325151523015). The authors also thank the Statistics Bureau of Shenzhen Municipality and the Hong Kong Census and Statistics Department for providing data on urban development.

\section{LITERATURE CITED}

Bornstein RD, Johnson DS (1977) Urban-rural wind velocity differences. Atmos Environ 11:597-604

Carlson TN, Arthur ST (2000) The impact of land use-land cover changes due to urbanization on surface microclimate and hydrology: a satellite perspective. Global Planet Change 25:49-65

> Chan HS, Kok MH, Lee TC (2012) Temperature trends in Hong Kong from a seasonal perspective. Clim Res 55: 53-63

Chandler TJ (1967) Absolute and relative humidities in towns. Bull Am Meteorol Soc 48:394-399

> Chen XL, Zhao HM, Li PX, Yin ZY (2006) Remote sensing image-based analysis of the relationship between urban heat island and land use/cover changes. Remote Sens Environ 104:133-146

> Chen J, Li QL, Niu J, Sun L (2011) Regional climate change and local urbanization effect on weather variables in southeast China. Stoch Env Res Risk A 25:555-565

Cheng $\mathrm{X}, \mathrm{Hu} F$ (2005) Numerical studies on flow fields around buildings in an urban street canyon and crossroad. Adv Atmos Sci 22:290-299

Chinese Academy of Social Sciences (2011) Blue book of cities in China: annual report on urban development of China No. 4. Pan J, Wei H (eds) Social Sciences Academic Press, Beijing (in Chinese)

Eliasson I (2000) The use of climate knowledge in urban planning. Landscape Urban Plan 48:31-44

- Ge Q, Wang F, Luterbacher J (2013) Improved estimation of average warming trend of China from 1951-2010 based on satellite observed land-use data. Clim Change 121: 365-379

Goldreich Y, Surridge AD (1988) A case study of low level country breeze and inversion heights in the Johannesburg area. J Climatol 8:55-66

> Granger CWJ (1969) Investigating causal relations by econometric models and cross-spectral methods. Econometrica 37:424-438

Grimmond S (2007) Urbanization and global environmental change: local effects of urban warming. Geogr J 173: 83-88

Hamburg M (1977) Statistical analysis for decision making, 3rd edn. Harcourt Brace Jovanovich, New York, NY

Howard L (1833) The climate of London deduced from meteorological observations, 3rd edn. Harvey and Darton, London

IPCC (2013) Summary for policymakers. In: Stocker TF, Qin D, Plattner GK, Tignor M and others (eds) Climate change 2013: the physical science basis. Contribution of Working Group I to the Fifth Assessment Report of the Intergovernmental Panel on Climate Change. Cambridge University Press, Cambridge

Kaufmann RK, Seto KC, Schneider A, Liu Z, Zhou L, Wang W (2007) Climate response to rapid urban growth: evidence of a human-induced precipitation deficit. J Clim 20:2299-2306

Lane DM (2014) Introduction to statistics. Rice University. http://onlinestatbook.com/Online_Statistics_Education.pdf

$>$ Lee DO (1991) Urban-rural humidity differences in London. Int J Climatol 11:577-582

Lenney MP, Woodcock CE, Collins JB, Hamdi H (1996) The status of agricultural lands in Egypt: the use of multitemporal NDVI features derived from landsat TM. Remote Sens Environ 56:8-20 
Li Q, Zhang H, Liu X, Huang J (2004) Urban heat island effect on annual mean temperature during the last 50 years in China. Theor Appl Climatol 79:165-174

Masson V, Lion Y, Peter A, Pigeon G, Buyck J, Brun E (2013) 'Grand Paris': regional landscape change to adapt city to climate warming. Clim Change 117:769-782

Mok HY, Leung YK, Lee T, Wu MC (2006) Regional rainfall characteristics of Hong Kong over the past 50 years. Conf on Changing Geography in a Diversified World, Hong Kong Baptist University, Hong Kong, PR China, 1-3 June 2006, HKO Reprint No. 646

Oke TR (1981) Canyon geometry and the nocturnal urban heat island: comparison of scale model and field observations. Int J Climatol 1:237-254

Oke TR (1987) Boundary layer climates. Routledge, London Stellmes M, Roder A, Udelhoven T, Hill J (2013) Mapping

Editorial responsibility: Eduardo Zorita, Geesthacht, Germany syndromes of land change in Spain with remote sensing time series, demographic and climatic data. Land Use Policy 30:685-702

Stewart ID, Oke TR (2012) Local climate zones for urban temperature studies. Bull Am Meteorol Soc 93: 1879-1900

> Wang J, Xu C, Hu M, Li Q, Yan Z, Zhao P, Jones P (2014) A new estimate of the China temperature anomaly series and uncertainty assessment in 1900-2006. J Geophys Res Atmos 119:1-9

Yu M, Liu Y, Dai Y, Yang A (2013) Impact of urbanization on boundary layer structure in Beijing. Clim Change 120: 123-136

> Zhou L, Dickinson RE, Tian Y, Fang J and others (2004) Evidence for a significant urbanization effect on climate in China. Proc Natl Acad Sci USA 101:9540-9544

Submitted: November 3, 2014; Accepted: February 10, 2015 Proofs received from author(s): April 17, 2015 